\title{
Learner-Centered Teaching: Can It Work in Kenyan Public Primary Schools?
}

\author{
Elizabeth Metto*, Lazarus Ndiku Makewa* \\ University of Eastern Africa, Baraton \\ *Corresponding author: jepkorireliza@gmail.com; ndikul@gmail.com
}

Received September 23, 2014; Revised October 09, 2014; Accepted December 08, 2014

\begin{abstract}
Learner-centered teaching is known, through research, to enhance effective learning. In these methods, learners play the key role in learning while teachers only help them to develop the necessary knowledge and skills that will enable them handle life issues and tasks independently. The developed countries to a greater extend practice these methods but many of the developing countries, Kenya included have continued to use the old teacher-centered teaching methods. Through a review of related literature, this study sought to uncover the factors that have hindered the use of learner-centered teaching methods in Kenyan public primary schools. The findings revealed multiple elements that have combined to prevent the practice of learner-centered teaching. These are grouped into teacher factors, teaching and learning material factors and learner factors. It was concluded that if Kenyan youth are to be prepared effectively to face life challenges of the $21^{\text {st }}$ century, the country's education stakeholders should endeavor to make teaching learner-centered rather than teacher-centered. The most important recommendation is that systematic teacher training should be provided for effective implementation of learner-centered teaching.
\end{abstract}

Keywords: learner-centered teaching, teacher factors, student factors, school factors, public primary schools

Cite This Article: Elizabeth Metto, and Lazarus Ndiku Makewa, "Learner-Centered Teaching: Can It Work in Kenyan Public Primary Schools?” American Journal of Educational Research, vol. 2, no. 11A (2014): 23-29. doi: 10.12691/education-2-11A-4.

\section{Introduction}

Kenya is a signatory to the Jomtien Agreement (1990) and the Dakar Framework for Action (2000) to achieve the Education for All (EFA) and Millennium Development Goals (MDG's) by 2015. Kenya vision 2030, a synthesis of these two agreements and other related policies, articulates the development of a middle income country in which all citizens will have embraced entrepreneurship, be able to engage in lifelong learning, learn new things quickly, perform more non-routine tasks, be capable of more complex problem -solving, willing and able to take more decisions, understand more about what they are working on, require less supervision, assume more responsibility, and as vital tools towards these ends; a better reading, quantitative, reasoning and expository skills (MOE, 2012 \& Orodho, 2013).

It is fourteen years since Kenya committed herself to the attainment of the six EFA goals at the World Forum held in Dakar, Senegal in April 2000 and it is only one year to the 2015 timeline aimed at the achievement of the MDG goals. However, the quality of education in the country is still critical. There still exist numerous challenges that need to be overcome in order to attain quality education for all children, youth and adults (Republic of Kenya/UNESCO, 2012). The focus on access and completion not only in Kenya, but also in the rest of Africa, ignores what students actually learn. Among children who reach fourth grade for example, 250 million could not be able to read or write. It is evident that students near the end of primary education have not yet acquired some of the knowledge and skills that are essential for full participation in modern societies, with a focus on reading, mathematics and science (The world we want, nd). It is not surprising therefore that among young men aged 15- 29 years, who had left school after six years of schooling, $6 \%$ were illiterate and $26 \%$ were semiilliterate. The figures are even worse for young women, with $9 \%$ illiterate and 30\% semi-illiterate after being in school for six years. The proportion of semi-illiterate or illiterate women after six years of schooling has worsened in recent years: In 2003, 24\% were in this situation, compared with 39\% in 2008.

For the majority of children in Kenya, as in other countries, primary education should equip them with adequate life and career skills to lead meaningful lives after school. In reality, however, the education offered in primary schools predominantly aims at preparing the students for secondary school (Sifuna \& Sawamura, 2008). Consequently, many children who terminate their formal schooling at primary level do so with very little in terms of gainful life skills.

Numerous research evidence associate learner-centered approach with the attainment of quality education, as compared with instructor-centered or teacher-centered approaches, where teaching is often focused on what the teacher knows and on unilateral transmission followed by recitation and evaluation, rather than on the facilitation of 
learning (Weimer, 2013 \& Vavrus et al., 2011). Emphasis on what instructors do often leads to students who are passive learners and who do not take responsibility for their own learning. On the other hand, teaching approaches that allow students to use hands, eyes, ears and the mind enhance effective learning and student's achievement (Mills, 1991; Sogomo, 2001; Waihenya, 2000 cited in Wachanga and Mwangi, 2004). In learnercentered teaching, teachers do not employ a single teaching method but use different types of methods that shift the role of the instructors from givers of information to facilitators of student learning (Blumberg, 2008). Mitchell (1997) in Carmichael (2009) noted that teaching strategies that promote student involvement and which students find meaningful will hold students' interest. In addition, learner-centered teaching helps students to take responsibility for their learning, emphasize high level thinking, focus on intrinsic rather than extrinsic motivation, and help the students remember important information. Learner-centered teaching such as cooperative learning (Wachanga \& Mwangi, 2004) and inquiry approach produce higher learning achievement and higher motivation (Kim, 2005 in Li, 2012). According to Schweisfurth (2011), learner-centered teaching is a solution to a myriad of problems including; a narrow examination-focused orientation in teaching, the need for inclusion of all learners, the need for a democratic political culture, need to solve the problem of poverty and elitism.

A summary of the advantages learner-centered teaching has been made, according to Vavrus et al., (2013), by the American Psychological Association (APA). In total, APA has developed 14 learner-centered principles that highlight some of the benefits that are believed to result from high-quality learner-centered instruction in the classroom. The most relevant principles as concerns this paper include:

a. The successful learner, over time and with support and instructional guidance, can create meaningful coherent representations of knowledge

b. The successful learner can link new information with existing knowledge in meaningful ways

c. The successful learner can create and use repertoire of thinking and reasoning strategies to achieve complex learning goals

d. Higher-order strategies for selecting and monitoring mental operations facilitate creative and critical thinking

e. The learner's creativity, higher order thinking, and natural curiosity all contribute to motivation to learn. Intrinsic motivation is stimulated by tasks of optimal novelty and difficulty, relevant to personal interests, and providing for personal choice and control

Many educational researchers have noted that learnercentered pedagogy helps students to develop critical thinking and the ability to apply complex ideas in real-life situations. The use of learner-centered approach in teaching and learning as shown by the APA, above would result in quality graduates that are the target of the nation as indicated in 2030 Vision. However, Majanga,et al., (2011) and Ackers and Hardman (2001) found out that the predominant teaching style in Kenya was characterized by the 'transmission of knowledge' and was teacher focused in nature. Students were motivated to participate but answered preplanned, “closed" questions and lessons often involved a high degree of choral response and repetition of memorized work. Teacher-pupil classroom interaction activities in the lower classes were not exploited to the full because teachers used traditional lecture method of teaching. Teachers did not involve all the pupils during classroom interaction. For example, teachers rushed over lessons interacting only with bright pupils ignoring weaker and slow learners, did all the work on the chalkboard, avoided group work which promotes pupil-pupil interaction and did not demonstrate any skill (Majanga, 2011).

Ackers and Hardman (2001) observed that there were few examples of interaction between teacher and pupils that extended or even encouraged higher order thinking because of the domination of the recitation mode, where typically the teacher asks a series of pre-planned questions, initiates all the topics, and rarely interacts with the substance of the pupils' answers, except to evaluate them. The teachers lectured on a topic for a large portion of a lesson and then questioned students to see what they were able to absorb. There was no inter- pupil interactions or discussions during class time. Rather, students spent the remainder of the class silently copying notes or answering questions from the board. As noted above, the use of learner-centered teaching approaches is still farfetched in Kenya and instead, teacher-centered approaches are still dominant.

In 2003, the Kenyan government introduced Free Primary Education (FPE). This was intended to enable many children who were out of school by then to enroll in school as a means to reducing poverty and inequalities in the Kenyan population. The response was overwhelming as many schools experienced high enrolment than their capacities could hold (Ogola, 2010). The new enrolment meant that 32,000 extra classrooms were required and consequently, 32,000 teachers were supposed to be hired. Anderson (2004) lamented that enrolment rates were up in most regions, but the quality of education remained low. Education for all is all very well, but good quality education for all is another story. Over enrolment triggers a chain reaction touching on teacher and facility adequacy, teaching methods, sitting arrangement, working space, examination and assessment, sanitation, among other things (Ogola, 2010).

According to a joint committee of ILO/UNESCO, there was insufficient evaluation of teacher training programs in relation to their impact on the teaching practice and on students' learning outcomes in the country (ILO/UNESCO, 2006). It appears that policy has changed more than practice when it comes to teachers actually utilizing learner-centered pedagogy. Limited reforms of teacher education programs across sub-Saharan Africa, Kenya included, partially explain the continued reliance on teacher-centered approaches (Vavrus, 2011). Such a scenario is disturbing and it was this that spurred the interest to undertake this review, which intended to find out why teachers in public primary schools have failed to use learner centered teaching methods that have the potential to yield better learner academic achievement than the teacher-centered methods that are still widely used by most of the teachers in the public schools of the country. 


\section{Problem Statement}

Research has shown that learner-centered teaching is an effective means to effective learning. Countries in the subSaharan Africa, Kenya included, have made effort to introduce these methods of teaching in schools. Though the Kenyan educational agencies have advocated for the use of these in primary schools, teachers in public primary schools in the country continue to use teacher-centered methods of teaching in classroom instruction. This work intends to unravel the reasons for this scenario.

\section{Teachers and Learner Centered Teaching}

Many researchers have proved that effective teachers generate the greatest opportunity for the students to learn and technically manage instruction. In addition, it has been found that teachers are the most important of the school-related factors affecting student achievement through their effectiveness (Orodho et al., 2013; UNICEF, 2012; Willitter et al., 2013 \& Vavrus et al., 2011). Learner-centered instructional strategies promote deep and lasting learning (Fahraeus, 2013).

In order to do their work effectively, teachers need to have high morale, motivation and a mastery of knowledge (Wachanga \& Mwangi, 2004). Such conditions will allow them (teachers) spark enthusiasm in students and utilize appropriate teaching strategies to increase learning. If a teacher is excited about the subject and shows the relevance of the assignments to the real world and to the students' future careers, he or she will be able to convince the students that the course content is interesting and relevant , and that the assignments are worthwhile (Taylor, 2014). However, this may not be the case in public primary schools in Kenya where, although teachers are expected to deal with the swollen class sizes, their salary negotiations with the government have not been met yet (Syomwene, 2013). Additionally, due to teacher shortages, the few teachers are given a heavy work load making it difficult for them to perform to their optimum level and realize quality education (UNESCO, 2004 cited in Syomwene, 2013).

In the view of ILO and UNESCO, the teaching profession has remained unattractive, especially in the third world countries, which include Kenya. This has led to a lowering of entry standards into the teaching profession, unqualified persons and/or school leavers with no training in teaching in both primary and secondary schools (ILO/UNESCO, 2006). Neither teacher education nor teaching has been professionalized in Kenya. Currently, the minimum entry grade for primary teacher education is C plain at Kenya Certificate of Secondary Education (KCSE). Students entering teacher training at universities are not the highest qualified students. Furthermore, there is no adequate screening of applicants for pre-service training to ensure that only those who have the interest in teaching join teacher training colleges. This is an indicator that those who choose to teach may not be happy and excited about their job and may lack the motivation to do whatever it takes including using learnercentered methods of teaching to ensure effective learning by their learners.
Teacher education in developing countries is rarely learner-centered and does not provide suitable models upon which teacher trainees can base their practice and is sometimes too theoretical ( Schweisfurth, 2011). According to ILO and UNESCO, the content of teacher training programs in Kenya did not focus adequately on reflective practice, active learning, innovation, creativity or partnership building. Additionally, there was often a disjuncture between the teacher training provided and the realities of the schools, their communities, and the world of work (ILO/UNESCO, 2006). Graduates of such training will not instill in learners what they were not instilled with in the first place.

Many scholars have pointed to the questionable impact of teacher training arguing that working habits acquired by persons who become teachers in the early stages of their own schooling tend to stay with learners to some degree throughout their learning or teaching careers. (MoE, 2012). This becomes worse for teachers when these "wrong methods of teaching" are carried on through college and to the field because some of the trainers that train them lack pedagogical training (ILO/UNESCO, 2006, \& MoE, 2012). Hence the teaching tends to be traditional and new training techniques are rarely implemented.

Bunyi et al., (2013) found that while teacher trainers in Kenya considered their trainees to be equipped with learner-centered teaching methods, in real sense, the trainees' participation in the lesson was in answering mostly recall questions, demonstrating what they had either been shown or told how to do and writing down notes. Trainees were not engaged in serious reflection and discussion about what they were learning, neither were they being challenged to think and demonstrate how they would use different methods to respond to particular needs in their future classes. It was apparent that the trainees were learning to use set methods and procedures and that in turn, they are likely to have difficulties helping different learners in their future classes learn to read. The hardest element to change and the major challenge facing the profession concerns changing instructional practices towards greater collaborative relationships between teachers and learners (MoE, 2012).

Raising teacher quality is a more effective measure to improve student outcomes (O.E.C.D 2013). OECD Secretary-General, Angel Gurria insisted on the need to push for better learner performance. "High-quality teachers are key to the successful implementation of educational policies. The bottom line is that the quality of an education system cannot exceed the quality of its teachers and work". Teacher training programs in Kenya are viewed as being largely unfit for purpose (MOE, 2012). New concepts related to teaching and learning need to be infused in teacher training. It is difficult for teachers to fully understand constructivist and student-centered instructional approaches and assessment practices without direct instruction (Li, 2012).

A substantial body of research suggests that teachers' beliefs and values about teaching and learning affect their teaching practices. According to Mullei, (1987) in Wachanga and Mwangi, (2004) having trained teachers does not necessarily improve the quality of education, but the way a teacher teaches is immensely influenced by the teacher's theoretical perspective and particularly his/her beliefs and perception towards the subject. Errington 
(2004) in O’Donnell et al., (2009) \& Stipek et al., (2001) argue that teachers' beliefs are probably the most important factor in determining the success or failure of a new approach to teaching. Teacher's perception of their teaching is a valuable variable in promoting effective teaching and learning. Schieb \& Karabeinick (2011) argued that successful curriculum change is most likely to occur when the curriculum reform goals relating to teachers' practices take into account the teachers' belief. Stipek et al.,(2001), for example, explained that teaching reforms in Mathematics cannot take place unless teachers deeply hold good beliefs about the teaching and learning changes. The adoption of learner-centered teaching methods is a demanding change which requires profound shifts in teacher-learner power relations and teacher professional learning (Schweisfurth, 2011).

Teachers at “disadvantaged schools” for instance, often hold low expectations of their students, which compound the low expectations student and their parents may also hold (Considine \& Zappalla, 2002).

Teacher shortages remain a major issue in education. In certain of the most acute cases, there is an existing shortfall of approximately 30 per cent of qualified teachers in primary and secondary schools, with even greater shortages in remote and high-risk areas (ILO/UNESCO, 2006; MOE, 2012). This has led to teacher-pupil ratio in some schools going as high as 1:90, which was far beyond the recommended maximum rate of 1:40 (Ogola, 2009 \& MOE, 2012). Over enrolment influences the quality of education. It does not allow the use of learner-centered teaching methods which facilitate effective learning. Rather, teachers find it impossible to pay attention to all learners, especially the slow ones (UNESCO, 2005). Moreover, the present primary school teacher is trained to handle an average of 40 pupils, not a crowd.

FPE led to the enrolment of over-age children and sometimes even adults in primary school. Teachers who were trained to teach young children find it hard to deal with learners of diverse ages and of diverse backgrounds in large classes (Ogola, 2010). Dawo (2011) observed that induction of teachers in Kenya was poorly done without clear objectives and without considering the needs to the novice teacher. She further noted that the experienced teachers themselves did not feel 'qualified' to do the induction.

Furthermore, many countries, Kenya being one of them, continue to lack systematic induction programs for beginning teachers or to make adequate provision for the professional development of teacher educators.Indoshi (2003) and Dawo (2011) say that induction of new qualified teachers in Kenya is haphazard and informal and teachers rarely benefit from it. Teacher-centered pedagogy is favored in a culture that teachers who are elders are supposed to be in control and learners are expected to be obedient and not to question authority (Schweisfurth, 2011).

In learner-centered instruction, the learner is allowed to choose what he wants to learn and how he wants to learn (Massouleh, \& Jooneghani, 2012). The teacher, for example, can allow the students to select their own topics, have groups work together on a writing project, and ask students to peer review their classmates' papers (Taylor, 2014). This concept has been controversial, mainly because it is susceptible to multiple interpretations. Some teachers react negatively to the concept because they feel that implicit in the notion, is a devaluing of their own professional roles. Others believe that it involves handing over to the learner duties and responsibilities that rightly belong to the teacher ( Massouleh, \& Jooneghani, 2012). Like, it does in other countries, this could explain why teachers in Kenya have not embraced the learner-centered teaching methods.

The MUSTER study reported by Vavrus et al., (2011) showed that student teachers' academic English, the medium of instruction was poor. This is a critical problem given that learner-centered teaching requires the use of clear and understandable language in giving directions, guiding and asking relevant questions that enable learners to effectively and gainfully engage in the learning process. This is not a wonder given that teaching does not attract the best academic performers in sub-Saharan countries, but it is those of average performance and below. BrockUtne (2007) cited in Vavrus et al., (2011) suggest that the predominant teaching style may in part reflect the difficulties in teaching in the second and third languages:

Teachers are asked to abandon a teacher style where students just copy notes from the blackboard, learn their notes by heart and repeat them at tests. Little thought has been given to the fact that this teaching style might be the only one possible when neither the teacher nor the students command the language of instruction (p. 512).

Lack of classroom experience, among tutors in colleges, make it hard for teacher to use learner-centered teaching methods. For instance, in Stuart's (2002) cited in Vavrus et al., (2011), a comparison of tutors at TTC's for primary teachers in Ghana, Lesotho, and Malawi found that the vast majority of tutors had degrees and even masters degrees but without primary teaching experience.

In Malawi, though the majority of older tutors had primary teaching experience, most of them held only diplomas, not bachelors or masters degrees. In Ghana, most tutors had completed their bachelors degrees and some also a masters degree, but the coursework they took in those categories was not designed to prepare them to be teacher educators (Vavrus et al., 2011).

The professional responsibilities of a teacher, consequently, cannot be understood simply in terms of acquiring a 'mechanical' teaching skills, but rather need to be seen in terms of developing professional expertise through the interplay of practice, scholarship and enquiry. They should be ready to read extensively to acquire new ideas, skills and knowledge, adapt new innovations, and do research in their own contexts and classes to prove whether what they read work for them or to modify some to these to suit their situation (Taber, 2010).

Adoption of Learner-centered approaches in teaching is challenging in Kenya because the national examinations continue to assess primarily student's knowledge of discrete, factual information, often referred to as declarative knowledge, rather than their critical, analytical skills (Woolfolk, 2011 cited in Vavrus et al., 2012)

\section{Teaching and Learning Resources and Learner- Centered Teaching}

In a student-centered classroom, you will not find a teacher standing at the front of the room talking to rows of seated students. Rather, you will likely see children 
working in small groups, moving about talking freely. Some children might be discussing a science experiment, while another group works on a model volcano, and a third prepares for a presentation. Interest centers would be located throughout the room, filled with books, materials, software, and projects designed to attract student interest on a wide array of topics. Finally you notice the teacher walking around the room, bending over to talk with individual students and small groups, asking questions and making suggestions (Massouleh, \& Jooneghani, 2012). Availability of adequate and relevant teaching-learning resources is very crucial in enhancing teacher effectiveness (Orodho et al., 2013). Equipment, books and other materials increase the learning opportunities within the physical environment of the classroom. It affects the behavior of learners and their attitudes towards schooling and learning (Anderson, 2004).

Various educational technologies have created tremendous opportunities to create effective studentcentered environments. For example, rich perceptual experience can be easily created in a computer-based learning environment for students to construct meanings; the internet brings in rich information that's socially and culturally familiar to the students. Computers act as the mentor that leads learners into the desirable learning tracks, and improve their learning performance (Li, 2012). Learning activities that involve computers will catch students' interest (Carmicheal et al., 2009). Kenyan public primary schools lack computer and internet facilities because the country spends only $4.2 \%$ of the current primary education budget on non-teacher salary inputs (World Bank, 2008). So, if few schools and colleges in the country have access to computers, internet and email facilities (Juma, 2001 cited in Syomwene, 2013), yet they receive a giant share of the funds allocated for the education sector, actually fourteen times higher than the primary sector (MoE, 2012), then it is obvious that there is virtually none of these facilities in public primary schools in the country. However, computer, internet and email facilities are essential for research and learning process. Lack of these impedes effective learning. But apart from the fact that computers are lacking in most schools in Kenya, the teachers lack computer literacy skills as well.

The textbook-pupil ratio (TPR), for both lower and upper primary schools in Kenya, had improved between 2003 from 1: 10 reaching 1:2 in 2009, while in upper primary it had improved from 1:2 in 2007 to almost 1:1 in 2009 for majority of schools. However, this has weakened sharply since 2009, and small schools with low enrolments have ratios far higher than the national average (MOE, 2012). This then means that public primary schools in Kenya cannot effectively use the learnercentered methods of teaching.

Scarcity of resources in public primary schools in Kenya is made worse by mismanagement, corruption and corruption related procurement, failures in monitoring, maintenance and equipping schools (MoE, 2012). Kimeu (2013) highlights that a report of June 2011 audit of the Ministry of Finance revealed that from 2005 to 2009, Ksh 4.2 billion (US\$ 48 million) intended for the Kenya Education Sector Support Program (KESSP) to fund primary education had been lost through misappropriation.

Free Primary Education in Kenya has brought about high enrolment in schools resulting to large class sizes, congested classrooms, (Majanga et al., 2011 \& Anderson, 2004), limited electricity, insufficient textbooks and desks for students plus learning materials like chalkboards and visual aids. Rukunga and Mutethia (2006) cited in Syomwene (2013), lament that water and sanitation facilities in public primary schools remained the same as they were before the increased enrolments that came with the start of Free Primary Education in 2003. These authors emphasize the importance of proper hygiene in school effectiveness for example in attracting enrolment of particularly adolescent girls and sustaining reduces burden of diseases and their effects on learning for example worm infestation among pupils. The fore going discussion indicate that lack of learning and teaching infrastructure and materials could have contributed to the continued use of teacher-learner teaching approaches rather than the learner-centered approaches that facilitate effective learning.

\section{Learners and Learner- Centered Teaching}

Certainly, learning is affected by a student's ability and attitude as well as resources in the child's school and home. Supportive parenting and stimulating home environments are among the strongest predictors of school performance during primary school and beyond (UNICEF, 2012). Many of the children in public primary schools in Kenya are from poor families that may not afford to offer the necessary background support to their children. The increased levels of poverty in the country make parents unable to pay school levies for their children, to feed their children properly and provide adequate health services (Syomwene, 2013). Low-income minority students in America experience less educational engagement (O’Donnell, 2009). The use of learner-centered approaches in teaching require that learners play an active role in class so if the learners remain passive, it might force the teacher to resort to the traditional teacher-centered approach that is more accommodative to passive learners.

Based on Piaget's theory of cognitive development, and supported by many cognitive psychologists, children are active thinkers who construct their own understanding of the events in the world around them. This notion implies that the school curricula should involve students as active participants in the learning process rather than absorbing knowledge by passively listening to teachers (Dembo, 1991).

In sub-Saharan Africa and parts of Asia, large class sizes continue to impede the achievement of EFA goals (ILO/UNESCO, 2006). Discipline and behavior problems arise among learners due to large class sizes (O'connor \& Geiger, 2009). Unlike classes in the developed countries, for example, the United States, where the typical public primary school classroom has 23.6 students in public schools, and 19.4 students in private school, public primary schools in Kenya have up to 90 learners or even more. Such numbers hinder the use of learner-centered teaching which require teachers' personalized attention to all the pupils and the giving of adequate assignments to test what has been taught and take full control of their classes (Majanga, 2011). 
One of the fundamental truths in education is that the knowledge, skills, aptitudes, attitudes and values with which students leave school or a particular teacher's classroom are influenced to a great extent by the knowledge , skills, aptitudes, attitudes and the values that students possessed when they entered the school or classroom. The best predictor of what students know and can do at the end of a certain period of schooling is the knowledge and skills with which they entered that period of schooling (Anderson, 2004). During the early years, children make leaps in physical, motor, social, emotional, language and cognitive skills development. The role of parents and key caregivers is primary for these developments. Parent's education goals for their children are also crucial for school success, as are their beliefs in, attitudes toward and commitment to education (UNICEF, 2012). High social status families may provide higher levels of psychological support for their children through environments that encourage the development of skills necessary for success at school (Considine \& Zappala, 2002). On the other hand, children reared in poverty areas are mostly not motivated to learn in school and are deprived of the stimuli that affect intellectual and cognitive development such as general sensory deprivation which results from lack of sufficient auditory and visual stimulation and poor verbal skills which stem from arrested language development in children's speech at home (Dembo, 1991). Since the majority of children in public primary schools in Kenya come from poor families, it is therefore unlikely that they will participate effectively in class if their teachers decide to use the learner-centered teaching method and may force the teacher continue using the traditional teacher-centered methods of teaching.

Large classes that characterize public primary schools in Kenya may hinder effective teaching and learning especially the use of learner-centered teaching because learners in a large class may be prevented from viewing the teacher while he/ she is presenting information to an entire class of students. For effective learning, each student need to have an unobstructed view of the teacher or of the information presented by the teacher. Further, when students are expected to engage in discussions with other students, the physical arrangement of the classroom should facilitate (e.g. circular arrangements) rather than inhibit (e.g. static row and column arrangements) this discussion. It is also required that when materials and equipment are needed, they should be readily available and in good working order (Anderson, 2004).

Second language, as a medium of instruction, is also known to challenge its members as opposed to the first language learners. In a study done in South Africa, struggling academically can lower ESOL learners' self esteem. Such children need parental assistance in learning the language but this is in many families is not available since parents are not educated (O’Connor \& Geiger,2009). Children living in homes where parents provide verbal engagement, interaction, stimulation and support do better in school than their peers who do not experience the same degree of interaction (UNICEF, 2012).

Students who are excited about learning will be passionate about learning. When students are excited about a topic and are committed to acquiring competence in their chosen field, they become more invested in the learning process (Taylor, 2014).
The more different students are from their teachers in terms of ethnicity, language, and culture, the more likely it is that students will come to believe that their teachers do not understand them. Furthermore, students may also have limited recreational and educational facilities within their schools (Considine \& Zappala).

The belief of “ being a good student” differs across cultures; students in collective cultures are more accustomed to listening quietly and taking notes, and are not used to collaborative problem-based learning ( $\mathrm{Li}$, 2012).

Expository teaching encourages competition among students but students who compete and fail or who do not even try to compete, resent those who succeed (Dembo, 1994; Sapon-Shevin and Schniedewind, 1990 in Wachanga and Mwangi, 2004). Teachers must, however, devise strategies to ensure that each student participates in the final product, since unscrupulous and lazy students may see collaborative work as a chance for a "free ride" and try to claim the work of others in the group as their own (Taylor, 2014).

\section{Conclusion}

This review sought to answer if the issue on if learnercentered teaching can work in Kenyan public primary schools. Based on the foregoing discussion, the answer is no. Despite the benefits of student centered teaching, many teachers in Kenya continue to use teacher-centered teaching approaches because teachers have not been trained and have never had personal experience on how to use this methods. Further, teachers cannot use these methods because of high teacher-pupil ratios, lack of or scarcity of teaching and learning materials and because the learners many of whom come from poor backgrounds lack the necessary knowledge and motivation that suit the practice of learner-centered teaching and learning.

\section{Recommendation}

If Kenya is to attain the desired goal of primary education of having graduates who are thinkers and innovators, then the government has to ensure the use of learner-centered teaching methods by; Planning and implementing systematic teacher training on learnercentered methods; Providing the necessary infrastructure that will allow the creation of small class sizes in which teachers can effectively use the learner-centered teaching methods; Employing qualified primary school teachers in public primary schools who have the necessary language, content and pedagogical skills to use learner-centered teaching methods in teaching. This will also reduce the high teacher-pupil ratios thus making it possible for the teachers to effectively use learner-centered teaching methods.

\section{References}

[1] Ackers, J. \& Hardman, F. (2001). Classroom interaction in Kenyan Primary schools. Compare. 31(2), 245-261.

[2] Anderson, L. W. (2004). Increasing teacher effectiveness. $2^{\text {nd }}$ Ed. Paris. International Institute for Educational Planning. 
[3] Blumberg, P. (2008). Developing learner-centered teachers: A practical guide for faculty. San Francisco: Jossey-Bass.

[4] Bunyi, G.W., Wangia, J., Magoma, C.M. \& Limboro, C.M. (2013). Teacher preparation and continuing professional development in Kenya: Learning to teach early reading and mathematics.

[5] Carmichael, C., Callingham, R., Watson, J. \& Hay, I. (2009). Factors influencing the development of middle school students' interest in statistical literacy. Statistics Education Research Journal, 8(1), 62-81.

[6] Considine, G. \& Zappala, G. (2002). The influence of social and economic disadvantages in the academic performance of school students in Australia. Journal of Sociology, 38:129.

[7] Fahraeus, A. W. E. (2013). Learner-centered teaching: Five key changes to practice. Book Review. Journal of the Scholarship of Teaching and Learning. 13 (4), 1-6.

[8] Li, N. (2012). Approaches to learning: Literature review. International Baccalaureate Organization.

[9] Majanga, E. K., Nasongo, J. W. \& Sylvia, V. K. (2010). The effects of class size on classroom interaction during Mathematics discourse in the wake of Free Primary Education: A study of public primary schools in Nakuru Municipality. Research Journal of Social Sciences. 3 (1), 44-49.

[10] Massouleh, N. S. \& Jooneghani, R. B. (2012). Learner- centered instruction: A critical perspective. Journal of Education and Practice, 3 (6).

[11] Ministry of Education (2012). A policy framework for education: Alligning education and training to the constitution of Kenya (2010) and Kenya Vision 2030 and beyond.

[12] Nungu, M. (2010). Universalizing Access to Primary Education in Kenya: Myths and Realities. Canadian Journal for New Scholars in Education. Special Issue, August 2010.

[13] O'Connor, J. \& Geiger, M. (2009). Challenges facing primary school educators of English second (or other) language learners in the Western Cape. South African Journal of Education. 29 (2).

[14] O’Donnell, M. A., Reeve, J. \& Smith, J. K. (2009). Educational Psychology: Reflection for Action. $2^{\text {nd }}$ Edition. U.S.A. John Wiley \& Sons.

[15] OECD (2013). Education at a glance, 2013. OECD indicators. OECD publishing.

[16] Ogola, F. O. (2010). Free education in Kenya's public primary schools. Addressing the challenges. Organization for Social Science Research in Eastern and Southern Africa (OSSREA). Addis Ababa, Ethiopia.

[17] Orodho, J.A., Waweru, P.N., Ndichu, M. \& Nthinguri, R. (2013). Basic education in Kenya: Focus on strategies applied to cope with school-based challenges inhibiting effective implementation of curriculum. International Journal of Education and Research.
[18] Report of the Joint ILO/UNESCO Committee of Experts on the Application of the Recommendations concerning teaching personnel. Ninth Session, November, 2006.

[19] Schieb, L. J. \& Karabenick, S. A. (2011). Teacher motivation and professional development: A guide to resources. Math and Science partnership-motivation Assessment program, University of Michigan, Ann Arbor.

[20] Schweisfurth, M. (2011). Learner- centered education in developing coutry contexts: From solution to problem? International Journal of Educational Development. 31: 425-432.

[21] Stipek, D. J., Givvin, K. B., Salmon, J. M. \& MacGyvers, V. L. (2001) Teachers beliefs and practices related to mathematics instruction. Teaching and Teacher Education, 17, pp. 213-226

[22] Syomwene, A. (2013). Factors affecting teachers' implementation of curriculum reforms and educational policies in schools: The Kenyan experience. Journal of Education and Practice. 4(22).

[23] Taber, K. S. (2010). Preparing teachers for a research-based profession in Zuljan, M. V. \& Vogrinc, J. ed. Facilitating effective student learning through teacher research and innovation. Faculty of Education, University of Ljubljan, Slovenia.

[24] Taylor, S. M. (2014). Term papers for hire: How to deter academic dishonesty. The journal of Adventist Education. February/March, 2014. http://jae.adventist.org.

[25] The World We Want. (nd). Making education a priority in the post-2015 development agenda. Report of the Global Thematic Consultation on education in the post-2015 development agenda.

[26] UNESCO (2005). Challenges of implementing free primary education in Kenya: assessment report. Kenya. Nairobi: Ministry of Education, Science \& Technology.

[27] UNICEF (2012). School readiness and transitions. Child Friendly Schools Manual. New York. UNICEF, Division of Communication.

[28] Vavrus, F., Thomas, M. \& Bartlett, L. (2011). Ensuring quality by attending to inquiry: Learner-centered pedagogy in sub-Saharan Africa. Addis Ababa. UNESCO: International institute for capacity building in Africa. 1 (11).

[29] Wachanga, S. \& Mwangi, J. G. (2004). Effects of the cooperative class experiment teaching method on secondary school students' chemistry achievement in Kenya's Nakuru District. International Education Journal 5 (1).

[30] Weimar, M. (2013). Learner-centerd teaching. Five key changes to Practice. $2^{\text {nd }}$ Ed. San Francisco. Jossey-Bass.

[31] Willitter, R. C., Ahmed, O. \& Kipng'etich , K. J.E. (2013). Towards learner centered pedagogies by teacher educators in Kenya: A study of Kericho Teachers' Training College. International Journal of Asian Social Science. 3 (1), 255- 265. 